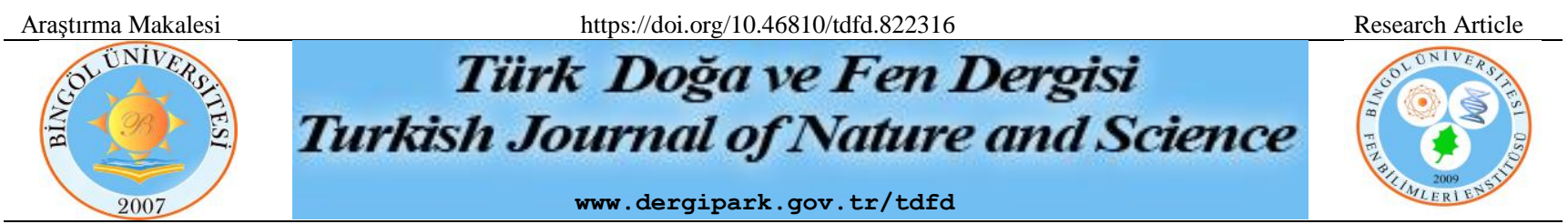

\title{
Sıcak Presleme Yöntemi ile TZ72-xMn Magnezyum Alaşımlarının Üretimi: Karakterizasyon ve Mekanik Özellikler
}

\author{
Ali ERÇETIN ${ }^{1 *}$ \\ ${ }^{1}$ Bingöl Üniversitesi, Mühendislik ve Mimarlık Fakültesi, Makine Mühendisliği Bölümü, Bingöl, Türkiye \\ Ali ERÇETIN ORCID No: 0000-0002-7631-1361 \\ *Sorumlu yazar: aliercetin@bingol.edu.tr
}

(Alınış: 06.11.2020, Kabul: 08.02.2021, Online Yayınlanma: 25.06.2021)

\begin{abstract}
Anahtar
Kelimeler

Magnezyum

alaşımı,

Sicak

presleme,

Toz

metalurjisi,

Mikroyap1,

Sinterleme,

Mekanik

özellikler
\end{abstract}

\begin{abstract}
Öz: Magnezyumun toz metalürjisinde kullanımını sınırlayıcı etmenler vardır. Toz halindeki $\mathrm{Mg}$ havayla temasında çabuk oksitlenebilmekte ve karıştırma gibi proseslerde tozların birbirlerine temasından kaynaklanan sürtünmeden dahi tutuşma riskini bünyesinde barındırmaktadır. $\mathrm{Mg}$ alaşımlarının toz metalurjisi yöntemiyle üretimini kolay kılacak önlemlerin sağlanmasına ve yeni $\mathrm{Mg}$ alaşımlarının bu yöntemlerle üretilmesine ihtiyaç vardır. Bu çalışmada, farklı oranlarda $\mathrm{Mn}$ içeriğine sahip $\mathrm{Mg} 7 \mathrm{Sn} 2 \mathrm{Zn}$-xMn magnezyum alaşımları sıcak presleme yöntemiyle başarılı bir şekilde üretilmiş ve Mn ilavesinin mikroyapı ve mekanik özelliklere etkisi incelenmiştir. Tozların karıştırılması öncesinde $\mathrm{Mg}$ alaşımlarına kaplama tekniği uygulanmıştır. Alaşımların üretiminde sıcak presleme ve grafit kalıp sistemi kullanılmıştır. Sinterleme işlemleri argon koruyucu gaz atmosferinde gerçekleştirilmiştir. Üretilen $\mathrm{Mg}$ alaşımlarına, yoğunluk ölçümü, metalografik analizler ve çekme testleri uygulanmıştır. Elde edilen sonuçlara göre, sıcak presleme yöntemiyle üretilen alaşımlardan ölçülen yoğunluk değerleri teorik yoğunluk değerlerine oldukça yakındır (\%98,97 ve üzeri bağıl yoğunluk). Basınç ve sinterleme proseslerinin eş zamanlı uygulanması sayesinde gözeneksiz mikroyapıya sahip alaşımlar üretilmiştir. Mikroyapıda ikincil intermetalik fazlar tespit edilmiş ve bu fazların tane sınırlarında yoğunlaştığı fark edilmiştir. Alaşımların hem dayanım hem de süneklik özellikleri artan Mn oranına bağlı olarak geliştirilmiştir. En yüksek çekme dayanımı (217,2 MPa) TZM720-B alaşımından elde edilmiştir.
\end{abstract}

\section{Production of TZ72-xMn Magnesium Alloys Through Hot Pressing Method: Characterization and Mechanical Properties}

Keywords
Magnesium
alloy,
Hot pressing,
Powder
metallurgy,
Microstructure,
Sintering,
Mechanical
properties

\begin{abstract}
There are limiting factors for the use of magnesium in powder metallurgy. Powdered $\mathrm{Mg}$ can oxidize quickly in contact with air and it has the risk of ignition even from friction caused by the contact of powders to each other in processes such as mixing. There is a need to provide measures to make the production of $\mathrm{Mg}$ alloys by powder metallurgy method easier and to produce new $\mathrm{Mg}$ alloys by these methods. In this study, Mg7Sn2Zn-xMn magnesium alloys with different ratios of Mn content were successfully produced by hot pressing method and the effect of $\mathrm{Mn}$ addition on microstructure and mechanical properties was investigated. Coating technique was applied to Mg alloys before mixing the powders. Hot pressing and graphite mold system are used in the production of alloys. Sintering processes were carried out in argon protective gas atmosphere. Density measurement, metallographic analysis and tensile tests were applied to the produced Mg alloys. According to the results obtained, the density values measured from the alloys produced by the hot pressing method are very close to the theoretical density values (relative densities with $98.97 \%$ and above). Alloys with non-porous microstructure were produced due to the simultaneous application of pressure and sintering processes. Secondary intermetallic phases were determined in the microstructure and it was noticed that these phases were concentrated at the grain boundaries. Both the strength and ductility properties of the alloys are developed depending on the increasing Mn ratio. The maximum tensile strength (217.2 MPa) was obtained from TZM720-B alloy.
\end{abstract}




\section{GíRIŞ}

Magnezyum alaşımları, sahip oldukları düşük yoğunluk, yüksek özgül mukavemet ve iyi sönümleme kabiliyeti gibi özellikler sayesinde birçok araştırmacı ve mühendislerin ilgi odağı haline gelmektedir [1-3]. Bunun neticesinde, alüminyum alaşımlarının geleneksel olarak kullanıldığı alanlarda (otomotiv, havacılık, askeri, ulaşım, bilgisayar ve mobil iletişim cihazları vb) magnezyum alaşımları hızla yer edinmektedir [4].

$\mathrm{Mg}$ alaşımının oda sıcaklığındaki mekanik özelliklerini arttıran $\mathrm{Al}$, ana alaşım elementi olarak birçok $\mathrm{Mg}$ alaşımının içeriğinde bulunmaktadır [3]. Ancak, 120 ${ }^{\circ} \mathrm{C}$ 'nin üzerindeki sicaklıklarda içyapıdaki $\mathrm{Mg}_{17} \mathrm{Al}_{12}$ fazının yumuşaması nedeniyle $\mathrm{Mg}$-Al alaşımının dayanımı azalmaktadır [3,5]. Eğer bu faz yerine ergime sıcaklığı daha yüksek olan bir faz oluşturulursa alaşımın sürünme dayanımı da geliştirilmiş olacaktır. $\mathrm{Mg}_{17} \mathrm{Al}_{12}$ fazına göre ergime sıcaklığ 1 oldukça yüksek olan $\mathrm{Mg}_{2} \mathrm{Sn}$ intermetalik fazı, magnezyuma kalay ilavesiyle mikroyapıda oluşturulabilmektedir [6]. Mg alaşımlarına Sn ilavesi ile ilgili çalışmalar literatürde oldukça fazladır [6-10]. Yüksek oranda Al içeren (AZ91 vb) $\mathrm{Mg}$ alaşımlarında tespit edilen bir diğer problem ise korozyon sorunudur. Bu alaşımlar genellikle sslak veya nemli ortamlarda korozyona uğrayabilmektedirler [4, 8]. Sn ilavesinin sadece mekanik özellikleri değil aynı zamanda korozyon özelliklerini de geliştirdiği ile ilgili çalışmalar mevcuttur [8, 11, 12]. Benzer bir şekilde korozyon dayanımını arttıran $\mathrm{Zn}$ ve $\mathrm{Mn}$ alaşım elementleri de, Sn alaşım elementi ile birlikte ilave edildiğinde korozyon dayanımında önemli gelişmeler sağlanabilmektedir [13, 14]. Zn ilavesinin mekanik özelliklerin gelişmesinde etkin rol oynadığ bilinmektedir. Ancak, Mn ilavesinin alaşımın mekanik özelliklerine etkisi ile ilgili çalışmalar genellikle saf Mg'ye ilavesiyle veya Al ile birlikte kullanılmasıyla ilgilidir [4, 14]. Al içermeyen $\mathrm{Mg}$ alaşımlarında kullanımı ile ilgili çok az sayıda çalışma mevcuttur.

Magnezyuma ilave edilen alaşım elementlerinin etkisi kadar üretim yöntemi de alaşımın özelliklerini önemli ölçüde etkilemektedir. Alaşımın mukavemetini ve sünekliğini geliştirmek için döküm sonrasında haddeleme [3, 15], ekstrüzyon [3, 16], dövme [3, 17] gibi termo-mekanik işlemler ilaveten uygulanmaktadır. Her bir ilave proses fazladan bir enerji gereksinimi ve artan maliyet anlamına gelmektedir. Bununla birlikte döküm yöntemiyle üretilen malzemelerin mikroyapısında segregasyon hataları da oluşabilmektedir [18-20]. Homojen ve daha ince taneli bir mikroyap1 eldesi toz metalurjisi yöntemi ile çok daha mümkündür [21-25]. Ancak Mg alaşımlarının bu yöntemle üretilmesinde iki önemli problemle karşılaşılmaktadır. Birisi, presleme işlemi uygulandıktan sonra sinterleme işleminin uygulanması ve toz metal parçanın istenilen ölçüde yoğunlaşamamasıdır. $\mathrm{Bu}$ nedenle, presleme ve sinterleme proseslerinin eş zamanlı uygulanması ile tam yoğunlaşma sağlanabilecektir $[8,9,26]$. Diğeri ise, $\mathrm{Mg}$ tozlarının bu yöntemde kullanımı esnasında hem oksitlenme hem de tutuşma gibi problemlerin gerçekleşebileceğidir. Bu sorunun çözümü için ise, tozların karıştırılmasından sinterleme işlemine kadarki süreçte $\mathrm{Mg}$ tozlarını koruyucu görevi üstlenecek bir bağlayıcı sisteminin $\mathrm{Mg}$ tozlarını kaplaması ile mümkündür [8, 24, 27].

Çalışmada, TZ72 magnezyum alaşımına farklı oranlarda Mn ilave edilerek, sicak presleme yöntemiyle toz metal parçaların üretilebilirliği ve farklı oranlarda $\mathrm{Mn}$ ilavesinin ürün özellikleri üzerindeki etkileri incelenmiştir.

\section{MALZEME VE YÖNTEM}

\subsection{Malzeme}

Çalışmada kullanılan yüksek saflıkta ve partikül boyutları oldukça küçük olan (10-45 mikron arası) $\mathrm{Mg}$, $\mathrm{Sn}, \mathrm{Zn}$ ve Mn tozlarına ait SEM görüntüleri Şekil1'de, tozlara ait bazı özellikler de Tablo 1'de verilmiştir. Kompozisyonların hassas karışım oranlarının sağlanabilmesi için tozların tartım işleminde $10^{-4} \mathrm{gr}$ hassasiyetinde Precision marka hassas terazi kullanılmıştır. TZ72 magnezyum alaşımına farklı oranlarda Mn ilavesi tasarlanarak 3 farklı kompozisyon oluşturulmuştur. Karışımların hazırlanmasından önce, $\mathrm{Mg}$ tozlarının oksidasyonunu önlemek için parafin kaplama tekniği kullanılmıştır $[8,9]$. Mg tozları hacimce $\% 20$ oranında parafin ile kaplanmıştır. Farklı kompozisyonlardaki karışımlara ilave edilecek olan Sn, $\mathrm{Zn}$ ve $\mathrm{Mn}$ alaşım tozlarının ağırlıklarının belirlenmesinde, bağlayıcı parafin ve matris $\mathrm{Mg}$ yüzdeleri dikkate alınarak hesaplamalar yapılmış ve tespit edilen ağırlıklarda alaşım tozları eklenmiştir (Tablo 1).

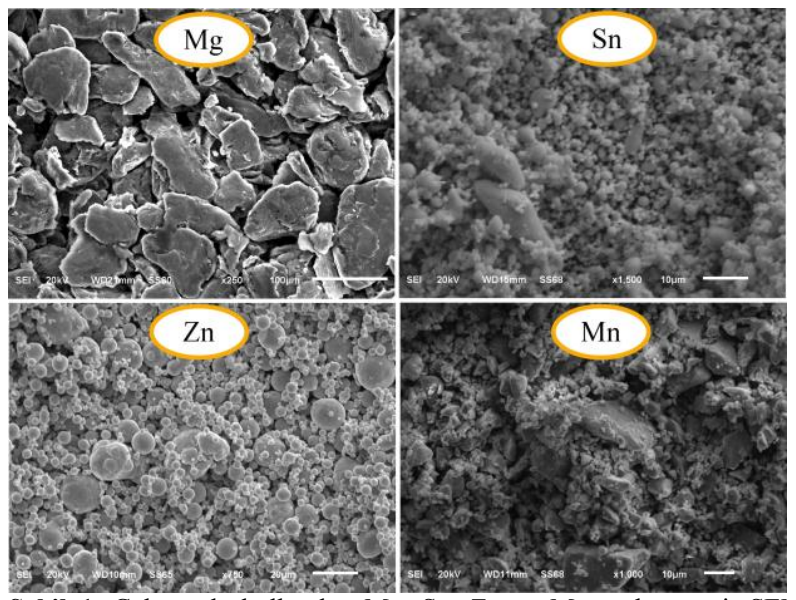

Şekil 1. Çalışmada kullanılan $\mathrm{Mg}, \mathrm{Sn}, \mathrm{Zn}$ ve $\mathrm{Mn}$ tozlarına ait SEM görüntüleri

Tablo 1. İlave edilen tozların özellikleri ve TZ72-xMn magnezyum alaşımlarının kimyasal kompozisyonları

\begin{tabular}{|c|c|c|c|c|}
\hline $\begin{array}{c}\text { Alaşım } \\
\text { kodlamaları }\end{array}$ & $\begin{array}{c}\text { Sn } \\
\% 99,9 \\
\text { saflık, } \\
10 \mu \mathrm{m} \\
\end{array}$ & $\begin{array}{c}\text { Zn } \\
\% 99,9 \\
\text { saflık, } \\
10 \mu \mathrm{m} \\
\end{array}$ & $\begin{array}{c}\text { Mn } \\
\% 99,8 \\
\text { saflık, } \\
10 \mu \mathrm{m} \\
\end{array}$ & $\begin{array}{c}\text { Mg } \\
\% 99,8 \\
\text { saflık, } \\
45 \mu \mathrm{m} \\
\end{array}$ \\
\hline TZ72 & 7 & 2 & 0 & Kalan \\
\hline TZM720-A & 7 & 2 & 0,15 & Kalan \\
\hline TZM720-B & 7 & 2 & 0,30 & Kalan \\
\hline
\end{tabular}

Karışımların basınç altında şekillendirilmesinde ve sinterlenmesinde grafit plakalar kullanılarak kalıplama 
tekniği kullanılmıştır [9]. Kalıp boşlukları 10 x $70 \mathrm{~mm}$ (en $\mathrm{x}$ boy) ölçülerinde oluşturulmuştur. $300{ }^{\circ} \mathrm{C}$ 'de bağlayıcı giderme işlemi işleminden sonra sinterleme işlemi, $30 \mathrm{MPa}$ basınç altında $610{ }^{\circ} \mathrm{C}$ 'de $50 \mathrm{dk}$ süre ile gerçekleştirilmiştir. Numunelerin oksidasyona maruz kalmasını önlemek için, sinterlemenin başlangıcından sonuna kadar ortama \%99,999 saflıkta argon gazı $9 \mathrm{~L} / \mathrm{dk}$ debi ile verilmiştir.

Sinterleme işlemi sonrasında her bir numuneye sırasıyla 240 grid-1500 grid arası zımparalama işlemleri gerçekleştirilmiştir. Numune yüzeylerinin parlatılması için $1-\mu \mathrm{m}$ boyutunda elmas süspansiyon kullanılmıştır. Dağlama işleminde, literatürde birçok uygulaması mevcut olan $[8,9,28,29]$ hacimce $\% 95$ etil alkol, $\% 5$ nitrik asit çözeltisi 50 saniye uygulanmıştır.

Numunelerin mikroyapı incelemelerinde taramalı elektron mikroskobu (SEM) ve elementel dağılım spektrometresi (EDS) kullanılmıştır. Oluşan fazların tayini için $\lambda=1,5405$ dalga boyunda, $0,02 \%, 4$ sn tarama hızında, X-ışını kırınımı (XRD) analizi gerçekleştirilmiştir. Sinterleme işleminin başarısını belirlemek için önce numunelerin gerçek yoğunlukları belirlenmiş, daha sonra bağı yoğunlukları hesaplanmiştır.

\subsection{Mekanik Testler}

Mekanik özelliklerin tespit edilmesi için çekme testleri uygulanmıştır. Her bir alaşım, literatürde uygulaması mevcut olan standartlarda [9], çekme numunesi haline getirilmiştir. Çekme testleri, maksimum $10 \mathrm{kN}$ kapasiteli Shimadzu marka cihazda $0,5 \mathrm{~mm} / \mathrm{dk}$ çekme hızında gerçekleştirilmiştir. Her bir kompozisyondan ayrı ayrı olmak üzere dört adet numuneye çekme testi uygulanmıştır. Dört adet numuneden elde edilen sonuçların ortalaması ilgili kompozisyondaki numuneye ait çekme testi sonucu olarak kabul edilmiştir.

\section{BULGULAR VE TARTISMAA}

S1cak presleme yöntemiyle üretilen TZ72-xMn magnezyum alaşımlarının ölçülen yoğunluk ve hesaplanan bağıl yoğunluk yüzdeleri Şekil 2'de verilmektedir. Artan Mn ilavesine bağlı olarak yoğunluk değerleri artarken, bağıl yoğunluk değerleri azalmaktadır. İlave edilen $\mathrm{Mn}$ oranı arttıkça, Mg'nin ağırlıkça yüzdesi aynı oranda azalmaktadır. Dolayısıyla artan Mn ile birlikte yoğunluk değerlerinin artması beklenen bir sonuçtur. Bağıl yoğunluk değerlerinin en düşük (TZ72: \%98,97) ile en yüksek (TZM720-B: $\% 99,58)$ oranları arasında \%0,61 gibi önemsenmeyecek bir fark vardır. Tüm alaşımların bağıl yoğunluk değerlerinin, sinterleme başarısı olarak kabul edilen \%95 değerinden ve benzer literatür çalışmalarından [30, 31] çok daha yüksek elde edilmesi, sıcak presleme yönteminin başarılı bir şekilde gerçekleştirildiğine işaret etmektedir.

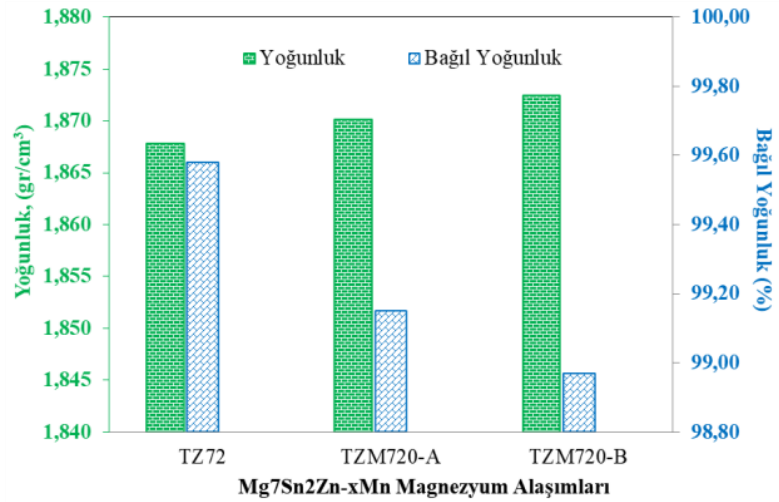

Sekil 2. Mg7Sn2Zn-xMn magnezyum alașımlarına ait yoğunluk ve bağıl yoğunluk değerleri

Mg7Sn2Zn-xMn magnezyum alaşımlarına ait XRD desenleri Şekil 3'te verilmektedir. XRD analizinde her bir alaşımda tespit edilen $\alpha-\mathrm{Mg}$ ve $\mathrm{Mg}_{2} \mathrm{Sn}$ fazlarıdır. Herhangi bir oksijen içerikli faz bulunmamaktadır. Dolayısıyla, alaşımların oksitlenmediğini söylemek mümkündür. Sn'ye ait herhangi bir pike rastlanmaması, Sn'nin Mg içerisine tamamının veya büyük bir miktarının difüzyon ile çözündüğünü ve $\mathrm{Mg}_{2} \mathrm{Sn}$ fazını oluşturduğunu göstermektedir. Diğer ilave edilen $\mathrm{Zn}$ ve $\mathrm{Mn}$ alaşım elementlerine ve bunların $\mathrm{Mg}$ ile yaptıkları herhangi bir intermetalik faza ait pike rastlanmamıştır. Literatürdeki çalışmalarda [9, 31, 32], Mg'ye ağırlıkça \%4'ün altında $\mathrm{Zn}$, ağırlıkça \%0,5'in altında $\mathrm{Mn}$ ilave edildiğinde, bu alaşım elementlerine veya $\mathrm{Mg}$ ile oluşturdukları fazlara ait pikler XRD analizinde tespit edilememiştir. Dolayısıyla, mevcut çalışmada ilave edilen $\mathrm{Zn}$ ve $\mathrm{Mn}$ alaşım elementlerinin literatürde belirtilen oranların oldukça altında olması nedeniyle, XRD analizinde bu alaşım elementlerine ait herhangi bir pik tespit edilemediğini söylemek mümkündür. 


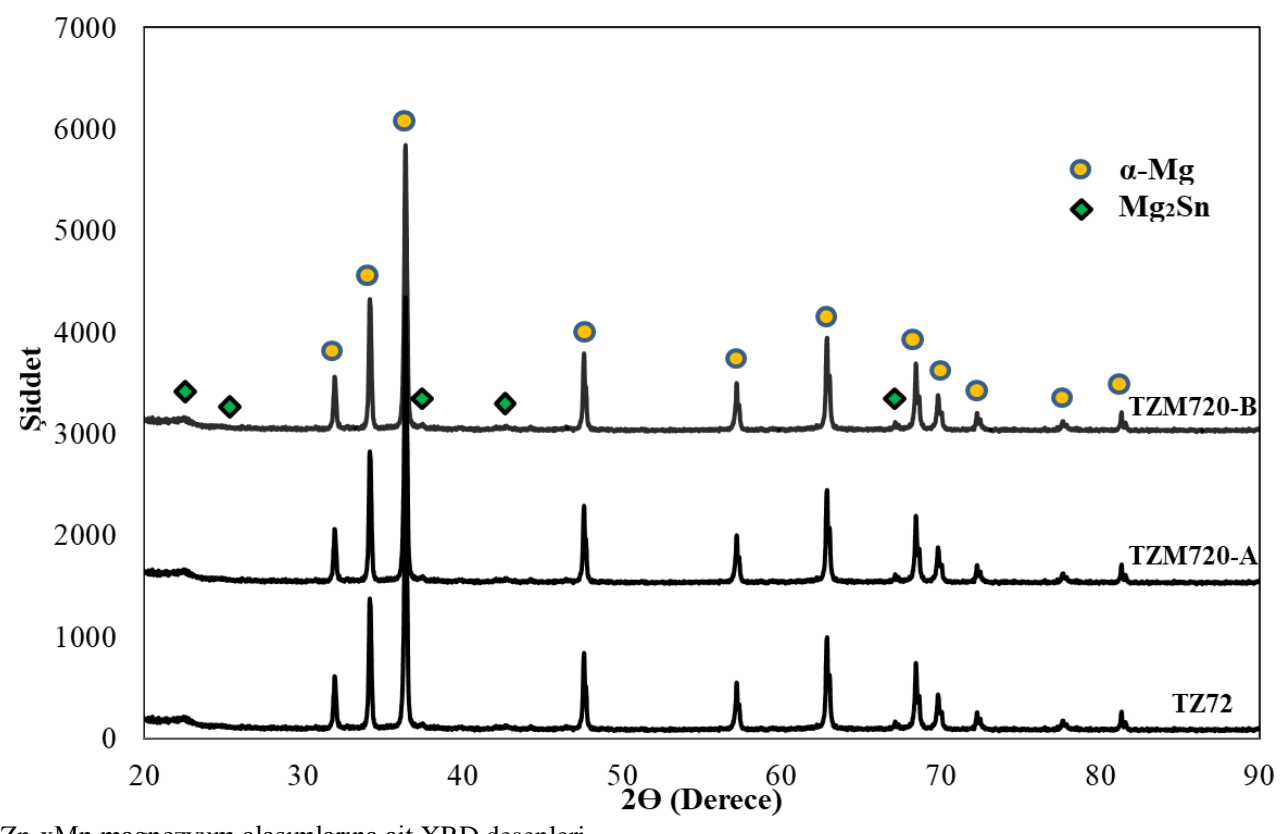

Şekil 3. Mg7Sn2Zn-xMn magnezyum alaşımlarına ait XRD desenleri

S1cak presleme yöntemiyle üretilen $\mathrm{Mg} 7 \mathrm{Sn} 2 \mathrm{Zn}-\mathrm{xMn}$ magnezyum alaşımlarına ait SEM görüntüleri Şekil 4'te verilmektedir. Her bir alaşıma ait SEM görüntüleri incelendiğinde, mikroyapıda gözenek oluşmadığı ve tanelerin homojen bir biçimde dağıldığı görülmektedir. Tane sınırlarında kırmızı oklarla gösterilen beyaz renkli noktasal yapıların XRD analizinde tespit edilen intermetalik $\mathrm{Mg}_{2} \mathrm{Sn}$ fazına ait olduğu düşünülmektedir. Alaşım içeriğinde bulunan Sn'nin sinterleme esnasında $\mathrm{Mg}$ içerisinde çözünmüş halde olduğu, hızlı soğuma esnasında tane içlerinden tahliye olurken tane sınırlarında $\quad \mathrm{Mg}_{2} \mathrm{Sn} \quad$ fazı olarak çökeldiği düşünülmektedir. Sn ilaveli $\mathrm{Mg}$ alaşımları ile ilgili bazı literatür çalışmalarında da $[6,7,9]$, mikroyapıda tane sınırları boyunca aynı yapıları görmek mümkündür. Dikkat çeken diğer bir durum ise, artan Mn oranına bağlı olarak mikroyapıdaki tane boyutlarının küçüldüğüdür. Mg-Mn faz diyagramına göre, Mn oda sıcaklığında Mg içerisinde ağırlıkça \% 2,2 oranında çözünmüş vaziyette kalabilmektedir. Mevcut çalışmada da, $\mathrm{Mg}$ içerisine Mn'nin neredeyse tamamının difüze olduğu ve tane düzenleyici etki sergilediği düşünülmektedir. Literatürde benzer bir çalışmada, Yu ve ekibi [33], Mg’ye farklı oranlarda Mn ilavesi yaparak mikroyapı özelliklerini araştırmışlardır. Elde ettikleri sonuca göre, partikül boyutu küçük Mn ilavesi ile, Mn'nin Mg içerisine difüzyonunun kolaylaştığını ve Mn'nin etkileyici bir şekilde tane düzenleyici etkisi sayesinde ince taneli mikroyapıya sahip alaşımlar elde edildiğini tespit etmişlerdir. Mevcut çalışmada da, artan Mn oranıyla birlikte mikroyapıdaki tane boyutlarının küçüldüğü Şekil 4 'te net bir şekilde görülmektedir.

Şekil 4'deki numune yüzeylerinden alınan EDS analizi sonuçları Şekil 5'te verilmektedir. Her bir alaşımdan elde edilen elementel sonuçlar, ilave edilen karışım oranları ile oldukça benzerdir. Alaşımlara ait XRD analizinde herhangi bir oksit pikine rastlanmamış olmasına rağmen EDS analizinde oksijen içeriği tespit edilmiştir. $\mathrm{Bu}$ durumun zımparalama ve parlatma işlemlerinde numune yüzeyinin suyla temasından dolayı oluştuğu düşünülmektedir. 

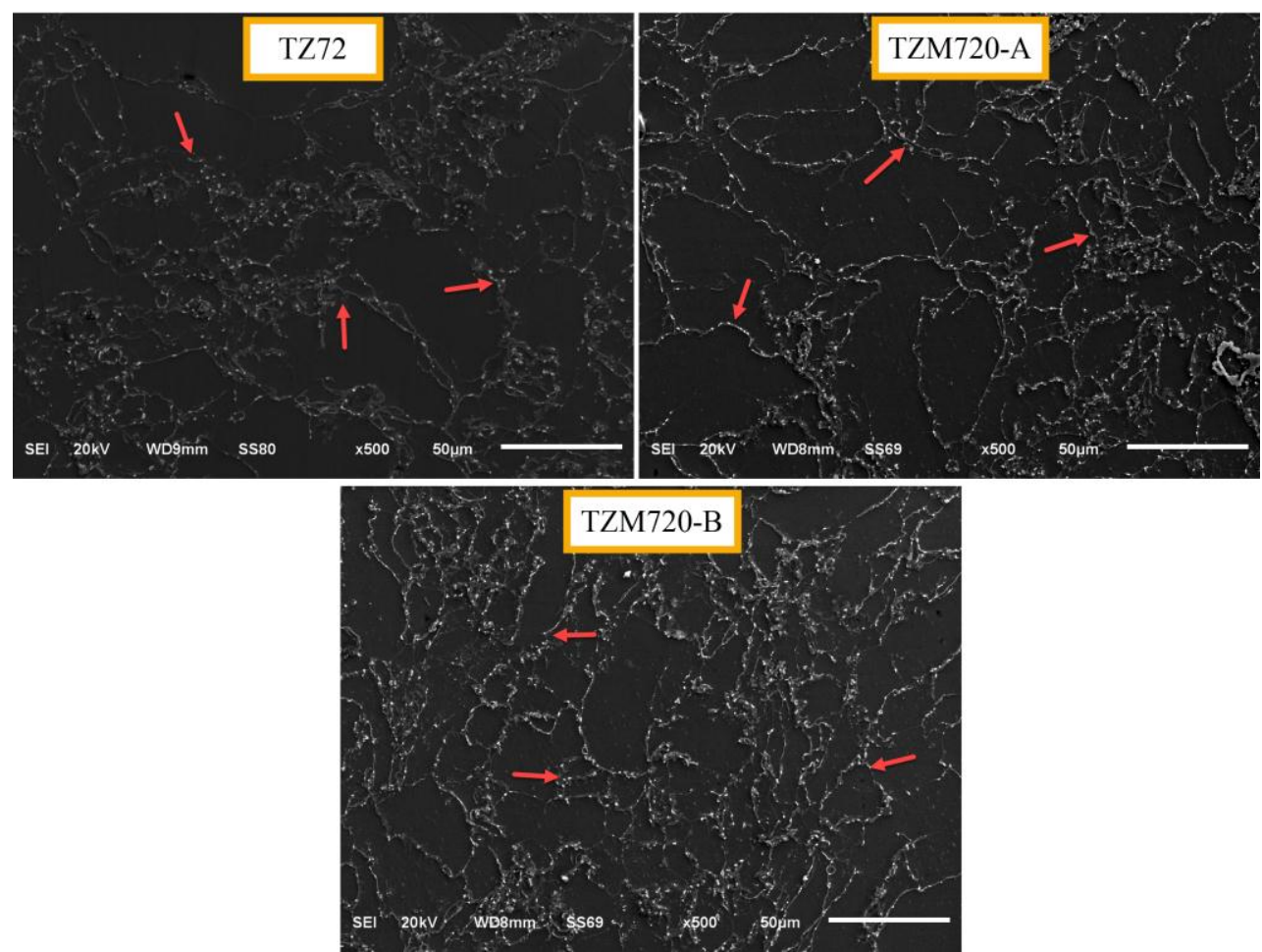

Şekil 4. Mg7Sn2Zn-xMn magnezyum alaşımlarına ait SEM görüntüleri
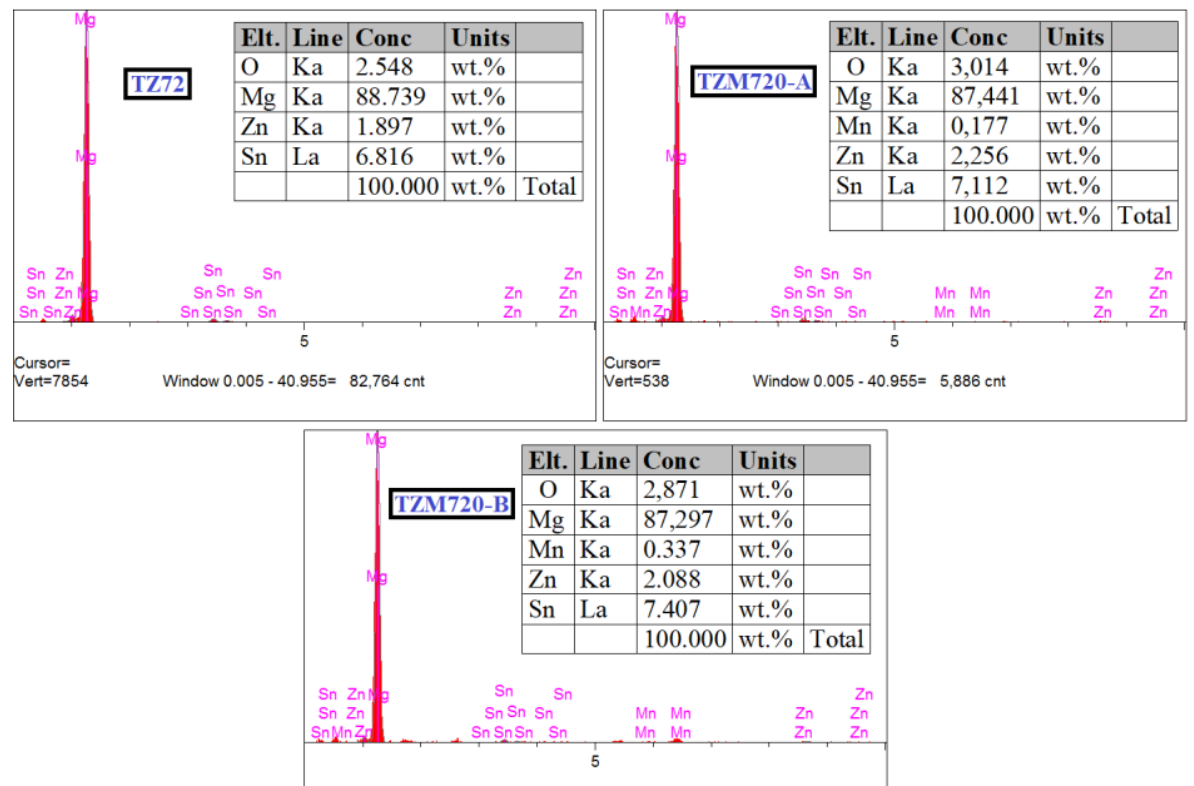

Şekil 5. Mg7Sn2Zn-xMn magnezyum alaşımlarına ait EDS analizi sonuçları

Farklı oranlarda Mn ilavesi içeren Mg7Sn2Zn-xMn magnezyum alaşımlarına ait çekme-uzama grafiği Şekil 6'da, elde edilen sonuçlar Tablo 2'de verilmektedir. Artan Mn oranına bağlı olarak alaşımların mukavemet değerleri etkili bir şekilde artış göstermiştir. Bununla birlikte süneklik değerlerinde de az da olsa artış gözlenmiştir. En yüksek dayanım ve süneklik özellikleri TZM720-B magnezyum alaşımından elde edilirken, en düşük dayanım ve süneklik özellikleri TZ72 magnezyum alaşımında tespit edilmiştir. SEM analizinde tespit edilen, artan Mn ilavesiyle daha ince taneli yapıların oluşması Hall-Petch etkisini de beraberinde getirmektedir. Tane boyutlarındaki küçülme ile tane sınırlarının uzunluğu da artacağından dislokasyon hareketleri zorlaşmaktadır. Dolayısıyla, Şekil 6'daki artan Mn oranına bağlı olarak mekanik özelliklerin gelişmesi bu duruma bağlanmaktadır. Benzer literatür çalışmasında [33], Mn ilavesiyle daha ince taneli mikroyapının elde edildiği alaşımların daha yüksek dayanıma sahip olduğu tespit edilmiştir. Bu çalışmada en yüksek dayanımın elde edildiği TZM720-B magnezyum alaşımı, literatürde döküm yöntemiyle üretilmiş ZX51 ve ZXM510 magnezyum alaşımlarından [3] \%50 ile \%80 aralığında daha iyi dayanım sergilemiştir. Bununla birlikte, en yüksek süneklik (\% 13 uzama) özellikleri de aynı alaşımdan elde edilmiştir. Candan vd. benzer bir çalışmada [13], AZ91 alaşımından yaklaşık olarak \%5 uzama elde etmişlerdir. Şimdiki çalışmada elde edilen uzama, Candan vd. elde ettiği uzama değerinden \%8 daha fazladır. 


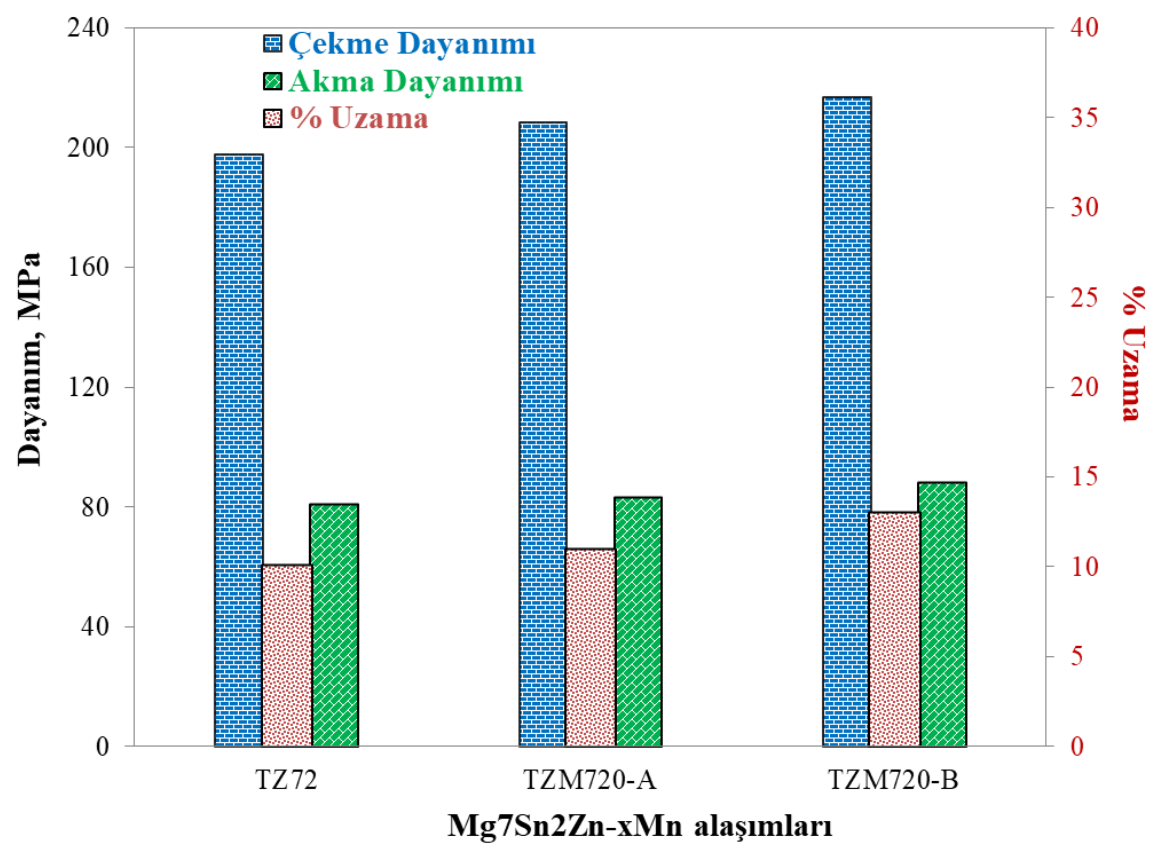

Şekil 6. Sıcak presleme yöntemiyle üretilen alaşımların çekme dayanımı ve \% uzama değerleri

Tablo 2. TZ72-xMn magnezyum alaşımlarının mekanik özellikleri

\begin{tabular}{|c|c|c|c|}
\hline $\begin{array}{c}\text { Alaşım } \\
\text { kodlamaları }\end{array}$ & $\begin{array}{c}\text { Çekme } \\
\text { Dayanımı, } \\
\text { (MPa) }\end{array}$ & $\begin{array}{c}\text { Akma } \\
\text { Dayanımı, } \\
\text { (MPa) }\end{array}$ & $\begin{array}{c}\text { Uzama, } \\
\mathbf{( \% )}\end{array}$ \\
\hline TZ72 & 198 & 81 & 10,1 \\
\hline TZM720-A & 208,8 & 83 & 11 \\
\hline TZM720-B & 217,2 & 88 & 13 \\
\hline
\end{tabular}

\section{SONUÇLAR}

$\mathrm{Bu}$ çalışmada TZ72 magnezyum alaşımı ve bu alaşıma farklı oranlarda $\mathrm{Mn}$ ilave edilen alaşımların sıcak presleme yöntemiyle üretimi başarıyla gerçekleştirilmiştir. Mn ilavesinin mekanik özelliklere etkisi araştırılmıştır. Döküm yöntemiyle üretilen $\mathrm{Mg}$ alaşımlarına kıyasla sıcak presleme ile üretilen $\mathrm{Mg}$ alaşımlarında gözeneksiz mikroyapılar elde edilmiştir. Basınç altında hızlı soğuma sayesinde, tane sınırlarında mekanik özellikleri olumlu etkileyen intermetalik ikincil fazlar oluşmuştur. Mn ilavesinin $\mathrm{Mg}$ alaşımlarında tane düzenleyici etkisi olduğu keşfedilmiştir. Artan Mn ilavesine bağlı olarak tane boyutlarında küçülmeler belirlenmiştir. Düşük oranlarda da olsa, Mn ilavesinin $\mathrm{Mg}$ alaşımının mekanik özelliklerini ve sünekliğini olumlu yönde etkilediği tespit edilmiştir.

Mn ilavesinin daha yüksek oranlarda ilavesi çalışılarak mekanik özelliklerin ve sünekliğin geliştirilebileceği üst sinırlar tespit edilebilir.

\section{Teşekkür}

$\mathrm{Bu}$ çalışmanın metalografik analizlerinde emeği geçen Bingöl Üniversitesi Merkezi Laboratuvarı ve çalışanlarına, çekme deneyi analizleri için Afyon Kocatepe Üniversitesi Merkezi Laboratuvar ve çalışanlarına teşekkür ederim. Sıcak presleme cihaz desteği için Bingöl Üniversitesi'ne ayrıca teşekkür ederim.

\section{KAYNAKLAR}

[1] $\mathrm{Hu} X S, \mathrm{Wu} \mathrm{K}$, Zheng MY. Effect of heat treatment on the stability of damping capacity in hypoeutectic Mg-Si alloy. Scripta Materialia. 2006;54(9):16391643.

[2] Laser T, Hartig CH, Nürnberg MR, Letzig D, Bormann R. The influence of calcium and cerium mischmetal on the microstructural evolution of $\mathrm{Mg}$ $3 \mathrm{Al}-1 \mathrm{Zn}$ during extrusion and resulting mechanical properties. Acta Materialia. 2008;56(12):27912798.

[3] Tong LB, Zheng MY, Xu SW, Kamado S, Du YZ, $\mathrm{Hu} \mathrm{XS}$, Wu K, Gan WM, Brokmeier HG, Wang GJ, Lv XY. Effect of Mn addition on microstructure, texture and mechanical properties of $\mathrm{Mg}-\mathrm{Zn}-\mathrm{Ca}$ alloy. Mater Sci Eng A. 2011;528:3741-3747.

[4] Khan SA, Miyashita Y, Mutoh Y, Sajuri ZB. Influence of $\mathrm{Mn}$ content on mechanical properties and fatigue behavior of extruded $\mathrm{Mg}$ alloys. Mater Sci Eng A. 2006;420:315-321.

[5] Levi G, Avraham S, Zilberov A, Bamberger M. Solidification, solution treatment and age hardening of a Mg-1.6wt.\%Ca-3.2wt.\%Zn alloy. Acta Materialia. 2006;54(2):523-530.

[6] Özgün Ö, Aslantaş K, Erçetin A. Powder metallurgy $\mathrm{Mg}-\mathrm{Sn}$ alloys: Production and characterization. Sci Iran. 2020;27:1255-1265.

[7] Liu H, Chen Y, Tang Y, Wei S, Niu G. The microstructure, tensile properties, and creep behavior of as-cast Mg-(1-10)\%Sn alloys. J Alloy Compd. 2007;440(1-2):122-126.

[8] Ercetin A, Özgün Ö, Aslantas K, Aykutoğlu G. The microstructure, degradation behavior and cytotoxicity effect of $\mathrm{Mg}-\mathrm{Sn}-\mathrm{Zn}$ alloys in vitro tests. SN Appl Sci. 2020;2:173.

[9] Ercetin A, Özgün Ö, Aslantas K. Investigation of mechanical properties of $\mathrm{Mg} 5 \mathrm{Sn}-\mathrm{xZn}$ alloys produced through new method in powder 
metallurgy, J Test Eval. 2021;49 https://doi.org/10.1520/JTE20200020

[10] Gökçe A. Toz metalurjisi yöntemiyle $\mathrm{Mg}-\mathrm{Sn}$ alaşımı üretimi ve karakterizasyonu. Acad Platform J Eng Sci. 2020;8:112-119.

[11] Zhou Y-Z, Wu P, Yang Y, Gao D, Feng P, Gao C, Wu H, Liu Y, Bian H, Shuai C. The microstructure, mechanical properties and degradation behavior of laser-melted MgSn alloys. J Alloy Compd. 2016;687:109-114.

[12] Shuai C, Zhou Y, Lin X, Yang Y, Gao C, Shuai X, Wu H, Liu X, Wu P, Feng P. Preparation and characterization of laser-melted $\mathrm{Mg}-\mathrm{Sn}-\mathrm{Zn}$ alloys for biomedical application. J Mater Sci Mater Med. 2017;28:1-8.

[13] Candan Ş, Çelik M, Candan E. AZ91 magnezyum alaşımında soğuma hızlarının mekanik ve korozyon özelliklerine etkisi. Bilecik Seyh Edebali Univ Fen Bil Derg. 2014;1(2):17-28.

[14] Kalaycı F, Zubaroğlu E. Çift merdaneli sürekli döküm tekniği ile üretilmiş $A Z$ ve $A M$ serisi magnezyum alaşımlarının korozyon davranışlarının karşılaştırılması. MSU Fen Bil Derg. 2017;5(2):391-398.

[15] Jin L, Dong J, Wang R, Peng LM. Effects of hot Rolling processing on microstructures and mechanical properties of $\mathrm{Mg}-3 \% \mathrm{Al}-1 \% \mathrm{Zn}$ alloy sheet. Mater Sci Eng A. 2010;527(7-8):1970-1974.

[16] Zhang BP, Geng L, Huang LJ, Zhang XX, Dong CC. Enhanced mechanical properties in finegrained $\mathrm{Mg}-1.0 \mathrm{Zn}-0.5 \mathrm{Ca}$ alloys prepared by extrusion at different temperatures. Scripta Mater. 2010;63(10):1024-1027.

[17] Garcés G, Müller A, O־norbe E, Pérez P, Adeva P. Effect of hot forging on the microstructure and mechanical properties of Mg-Zn-Y alloy. J Mater Process Technol. 2010;206(1-3):99-105.

[18] Avinash L, Kumar H, Parthasarathy A, Varun Kumar KN, Sajjan B. The effect of ceramic reinforcement on the microstructure, mechanical properties and tribological behavior of $\mathrm{Al}-7.5 \% \mathrm{Si}$ 0.5\% Mg alloy. AMM 2017;867:3-9.

[19] Parthasarathy A, Avinash L, Varun Kumar KN, Sajjan B, Varun S. Fabrication and characterization of $\mathrm{Al}-0.4 \% \mathrm{Si}-0.5 \% \mathrm{Mg}$ - SiCp using permanent mould casting technique. AMM 2017;867:34-40.

[20] Lakshmi Narayana KS, Shivanand HK, SachinKumar P. Mechanical and tribological behavior of e-glass fiber reinforced aluminum matrix composites produced by stir casting: A review. Int $\mathrm{J}$ Mech Product Eng Res Develop. 2018;8(8):39-50.

[21] Ercetin A, Aslantaş K. The effect of different cutting parameters on cutting force, tool wear and burr formation in micro milling $\mathrm{WCu}$ composite material fabricated via powder metallurgy. Tr J Nature Sci. 2016;5(2):1-5.

[22] Ercetin A, Aslantaş K. Production of $\mathrm{WCu}$ electrical contact material via conventional powder metallurgy method: Characterization, mechanical and electrical properties. $\operatorname{Tr} \mathrm{J}$ Nature Sci. 2017;6(1):37-42.
[23] Özgün Ö, Ercetin A. Microstructural and mechanical properties of $\mathrm{Cr}-\mathrm{C}$ reinforced $\mathrm{Cu}$ matrix composites produced through powder metallurgy method. Tr J Nature Sci. 2017;6(2):1-6.

[24] Turan ME, Sun Y, Akgul Y. Mechanical, tribological and corrosion properties of fullerene reinforced magnesium matrix composites fabricated by semi powder metallurgy. J Alloy Compd. 2018;740:1149-1158.

[25] Özgün Ö, Gülsoy HÖ. Toz enjeksiyon kalıplama yöntemi ile üretilen FeCo alaşımlarının mikroyapı ve mekanik özelliklerinin araştırılması. Tr J Nature Sci. 2020;9(1):6-11.

[26] Turan ME, Sun Y, Akgul Y, Turen Y, Ahlatci H. The effect of GNPs on wear and corrosion behaviors of pure magnesium. J Alloy Compd. 2017;724:14-23.

[27] Ercetin A, Aslantas K, Özgün Ö. Micro-end milling of biomedical TZ54 magnesium alloy produced through powder metallurgy. Mach Sci Technol. 2020;24(6):924-947.

[28] Nayyeri G, Mahmudi R. Enhanced creep properties of a cast $\mathrm{Mg}-5 \mathrm{Sn}$ alloy subjected to agingtreatment. Mater Sci Eng A. 2010;527:4613-4618.

[29] Wahba M, Katayama S. Laser welding of AZ31B magnesium alloy to $\mathrm{Zn}$-coated steel. Mater Des. 2012;35:701-706.

[30] Akkaş M, Boz M. Investigation of the compressibility and sinterabilty of AZ91 powder production and particle production by gas atomisation method. J Magnesium Alloy. 2019;7:400-413.

[31] Qi F, Zhang D, Zhang X, Xu X. Effects of Mn addition and $X$-phase on the microstructure and mechanical properties of high-strength $\mathrm{Mg}-\mathrm{Zn}-\mathrm{Y}$ Mn alloys. Mater Sci Eng A. 2014;593:70-78.

[32] Liao H, Kim J, Liu T, Tang A, She J, Peng P, Pan F. Effects of $\mathrm{Mn}$ addition on the microstructures, mechanical properties and work-hardening of $\mathrm{Mg}$ 1Sn alloy. Mater Sci Eng A. 2019;754:778-785.

[33] Yu Z, Tang A, Wang Q, Gao Z, He J, She J, Song K, Pan F. High strength and superior ductility of an ultra-fine grained magnesium-manganese alloy. Mater Sci Eng A. 2015;648:202-207. 